\title{
Pengaruh Autenthic Leadership, Person Job Fit, dan Quality of Work Life Terhadap Komitmen Afektif Guru (Studi Pada SMK Negeri 1 Ambal)
}

\author{
Ngaenurrohmah ${ }^{1}$, Anton Prasetyo ${ }^{2}$ \\ 1,2 Universitas Putra Bangsa \\ ngaenurrohmah123@gmail.com
}

ARTICLE INFO

Article History:

Received: June 19th 2021

Accepted: July $10^{\text {th }} 2021$

Published: July $31^{\text {st }} 2021$

Keywords:

Autethic Leadership, Person Job Fit, Quality of Work Life

\begin{abstract}
Penelitian ini dilakukan untuk mengetahui pengaruh autethic leadership, person job fit, dan quality of work life terhadap komitmen afektif guru SMK Negeri 1 Ambal. Data yang digunakan dalam penelitian ini adalah data primer. Penelitian ini menggunakan 37 responden sebagai sampel penelitian yang ditarik berdasarkan sampling jenuh. Pengambilan data menggunakan kuesioner berdasrkan skala likert yang telah dimodifikasi dengan 4 skala. Metode analisis data menggunakan analisis regresi linear berganda dengan bantuan SPSS 23 for windows. Hasil penelitian berdasarkan uji $\mathrm{t}$ menunjukkan bahwa variabel autenthic leadership tidak berpengaruh signifikan terhadap komitmen afektif guru SMK Negeri 1 Ambal. Variabel Person job fit tidak berpengaruh terhadap komitmen afektif guru SMK Negeri 1 Ambal. Variabel quality of work life berpengaruh signifikan terhadap komitmen afektif guru SMK Negeri 1 Ambal.Variabel autenthic leadership, person job fit, dan quality of work life secara bersama-sama berpengaruh signifikan terhadap komitmen afektif guru SMK Negeri 1 Ambal.
\end{abstract}

\section{Pendahuluan}

Persaingan di era globalisasi menuntut SDM yang berkualitas, hal ini dikarenakan SDM mempunyai peran yang sangat penting dalam pengembangan dan pencapaian tujuan organisasi. Salah satucarauntukmembentuk SDM yang berkualitas yakni melalui pendidikan. Menurut Kurniawan (2017) pendidikan adalah mengalihkan (menurunkan) berbagai nilai, pengetahuan, pengalaman dan keterampilan kepada generasi yang lebih muda sebagai usaha generasi tua dalam menyiapkan fungsi hidup generasi selanjutnya, baik jasmani maupun rohani.

Tujuan Pendidikan Nasional menurut Undang-Undang No. 14 Tahun 2005, Pembukaan Undang-Undang Dasar Negara Republik Indonesia Tahun 1945 adalah untuk melindungi segenap bangsa, dan seluruh tumpah darah Indonesia dan untuk memajukan kesejahteraan umum, mencerdaskan kehidupan bangsa, dan ikut melaksanakan ketertiban dunia berdasarkan Kemerdekaan, Perdamaian Abadi, dan Keadilan Sosial. Pemerintahan Indonesia dalam upaya meningkatkan kualitas pendidikan tidak henti-hentinya melakukan 
berbagai upaya salah satunya menyiapkan tenaga-tenaga pendidik agar lebih berkompenten dan profesional. Guru merupakan tenaga profesional yang melakukan tugas pokok dan fungsi untuk meningkatkan pengetahuan dan wawasan, skill, mental dan akhlak pesertadidik. Hal tersebut tertuang dalam Undang-undang Nomor 14 Tahun 2005 tentang Guru dan Dosen yang menyatakan bahwa Guru adalah pendidik professional dengan tugas utama mendidik mengajar, membimbing, mengarahkan, melatih, menilai, dan mengevaluasi peserta didik pada pendidikan anak usia dini jalur pendidikan formal, pendidikan dasar, dan pendidikan menengah.

Tugas guru menjadi sangat penting karena guru sebagai ujung tombak pendidikan diharuskan meningkatkan kompetensi dan aktif mengaktualisasi diri dengan mengembangkan materi pembelajaran yang diampu secara kreatif, mengembangkan keprofesionalan secara berkelanjutan dengan melakukan tindakan reflektif, dan komunikasi untuk mengembangkan diri. Permasalahan SDM dalam sekolah menuntut untuk diperhatikan, sebab secanggih apapun teknologi yang dipergunakan dalam sekolah, guru yang akan menjalankannya. Hal ini menunjukkan bahwa tanpa adanya dukungan kualitas yang baik dari guru, sekolah tidak akan mencapai keberhasilannya.

Guru memainkan peran yang sangat penting dalam proses belajar siswa dan merupakan sumber daya yang berharga dalam sebuah organisasi, dalam hal ini sekolah adalah tonggak dari tujuan pembangunan nasional membutuhkan peran guru sebagai subjek pembangunan nasional. Ini berarti untuk mencapa mutu lulusan yang diinginkan, mutu tenaga pendidik (guru) dan tenaga kependidikan harus ditingkatkan. Dengan meningkatkan kualitas guru, maka guru dapat memainkan perannya sebagai subjek pembangunan nasional dengan baik dimana tujuan tersebut tersirat dalam visi misi sekolah. Sebagai bagian penting dari penyelenggaraan pendidikan tersebut guru harus mempunyai komitmen yang tinggi. Komitmen menjadi sangat penting karena komitmen merupakan hal yang paling mendasar dalam melaksanakan suatu pekerjaan terutama dalam dunia pendidikan.

Menurut Soekamto et al. (2012) Komitmen afektif adalah bentuk komitmen yang merujuk pada kuatnya keinginan emosional pegawai guna beradaptasi dengan nilai-nilai pada organisasinya. Komitmen dapat dilakukan karena sukarela atau terpaksa tergantung pada situasi masing-masing guru yang berfokus kepada perilaku manusia. Guru yang memiliki komitmen afektif akan menyatu terhadap organisasi, menerima tujuan dan nilai organisasi serta bersedia bekerja lebih untuk kepentingan organisasi. Selanjutnya dikemukakan oleh Zurnali dalam Susilo, dkk (2016) komitmen afektif adalah perasaan cinta pada seseorang terhadap organisasi yang memunculkan kemauan untuk tetap tinggal dan membina hubungan sosial serta menghargai nilai hubungan dengan orang, karena telah menjadi anggota orgaanisasi.

Salah satu variabel yang diduga berpengaruh terhadap komitmen afektif adalah autenthic leadership. Pentingnya para pemimpin dalam keberhasilan organisasi membuat akademisi maupun praktisi terus mengeksplorasi gaya kepemimpinan yang dianggap paling efektif. Menurut Oh dan Oh (2017) menemukan bahwa pegawai yang memiliki pemimpin dengan gaya kepemimpinan otentik akan lebih bersedia untuk menunjukkan komitmen yang lebih afektif terhadap organisasi masing-masing. Milic, dkk (2017) menunjukkan bahwa kepemimpinan otentik mendorong kinerja organisasi melalui komitmen afektif untuk tujuan organisasi. Hasil penelitian yang dilakukan oleh Mayora dan Purwanto (2019) yang menunjukkan bahwa autenthic leadership berpengaruh positif terhadap komitmen afektif 
pada PT Dasa Anugerah Sejati. Hal ini berarti bahwa kepemimpinan otentik akan meningkatkan komitmen afektif guru, kemudian komitmen afektif guru akan menurunkan keinginan guru untuk meninggalkan organisasi.

Selain itu faktor lain yang mempengaruhi komitmen afektif yaitu kesesuaian guru tersebut dengan pekerjaanya (person job fit). Seorang guru yang tidak memiliki kesesuaian akan pekerjaannya, diprediksi sulit untuk menunjukkan keprofesionalnya karena yang bersangkutan merasa tidak sesuai dengan jenis pekerjan yang diperoleh, sehingga timbul rasa enggan untuk meningkatkan kemampuannya. Sebaliknya bagi guru yang merasakan sesuai dengan jenis pekerjaan (profesinya), maka akan berusaha untuk terus berusaha, terus belajar, meningkatkan kemampuan dan keterampilan sehingga dapat bekerja dengan optimal, karena kesesuaian merupakan dasar awal seseorang untuk menentukan langkah selanjutnya Ching dan Kee (2012). Alniack, dkk (2013) dalam hasil penelitiannya menjelaskan beberapa faktor kontigensi yang dapat mengubah hubungan antara komitmen organisasi dan intensi turnover sampai batas tertentu. Hasil penelitian yang dilakukan oleh Anindita (2019) semua variabel berpengaruh positif terhadap kinerja pegawai melalui komitmen afektif pada kantor dinas cabang dinas pendidikan wilayah kota Surabaya. Apabila pimpinan ikut bertindak dan mendorong bawahannya untuk mendalami soft skill nya, dengan melihat soft skill dari masing-masing guru akan mulai meningkat dan para guru merasa komitmen afektifnya sudah baik.

Faktor yang juga mempengaruhi komitmen afektif adalah kualitas kehidupan kerja (Quality of Work Life). Menurut Angelia (2013) kehidupan kerja yang berkualitas akan dapat menarik pegawai untuk lebih kreatif, betah, atau berkomitmen tinggi dan bersedia mengerahkan segala potensi yang dimiliki dilingkungan organisasi. Jadi semakin baik quality of work life disuatu organisasi, semakin tinggi juga komitmen afektif. Karena dengan terpenuhinya kebutuhan guru, guru tersebut akan merasa harus belajar lebih giat dan disiplin dalam bekerja untuk mencapai tujuan organisasi. Hasil penelitian yang dilakukan oleh Fitriyani (2019) Quality of Work Life berpengaruh terhadap komitmen afektif kerja PNS Dinas Pendidikan Kabupaten Kebumen. Guru yang mempunyai QWL yang tinggi maka akan memiliki komitmen afektif yang tinggi juga dengan adanya dorongan, kemauan yang besar untuk maju kedepannya dan lebih baik lagi komitmen afektif yang dimiliki.

\section{Kajian Teori dan Telaah Literatur}

\section{Komitmen Afektif}

Menurut Zurnali dalam Susilo, dkk (2016) komitmen afektif adalah perasaan cinta pada seseorang terhadap organisasi yang memunculkan kemauan untuk tetap tinggal dan membina hubungan sosial serta menghargai nilai hubungan dengan orang, karena telah menjadi anggota orgaanisasi.

Indikator komitmen afektif menurut Allen dan Mayer dalam Munarsih dan Sudarma (2016) sebagai berikut:
a. Rasa senang
b. Rasa memiliki
c. Keterikatan emosional
d. Makna Pribadi 


\section{Autenthic Leadership}

Kepemimpinan otentik (autenthic leadership) didefinisikan sebagai pola perilaku pemimpin yang cenderung mendorong kesadaran diri yang lebih besar, perspektif moral yang diinternalisasikan, keseimbangan pengolahan informasi, dan transparasi relasional dan membina pengembangan diri yang positif Azanza et al. (2015). Tolak ukur autenthic leadership menurut Avolio, dkk (2014):
a. Self awareness
b. Transparansi
c. Moral
d. Balanced Processing

\section{Person Job Fit}

Person job fit mengukur bagaimana karakteristik individu memenuhi tuntutan lingkungan kerja khususnya terhadap pekerjaan mereka menurut Lu et al. (2014). Person job fit didefinisikan sebagai kompatibilitas antara individu dan pekerjaan atau tugas yang mereka lakukan ditempat kerja.

Berdasarkan dimensi dari penelitian yang dilakukan oleh Daniel dan Elizabeth (dalam Hanum 2014), maka indikator yang digunakan pada variabel person job fit adalah sebagai berikut:
a. Nilai
b. Tujuan
c. Kebutuhan psikologis
d. Minat
e. Gaji
f. KSAOs (Knowlegde, Skill, Attitude, Others)

\section{Quality Of Work Life}

Menurut Angelia (2013) kehidupan kerja yang berkualitas akan dapat menarik pegawai untuk lebih kreatif, betah, atau berkomitmen tinggi dan bersedia mengerahkan segala potensi yang dimiliki dilingkungan organisasi.

Menurut Wayne (dalam Suratman 2017) indikator QWL (Quality of Work Life) sebagai berikut:
a. Imbalan yang memadai
b. Pertumbuhan dan pengembangan
c. Lingkungan kerja
d. Restrukturisasi kerja 


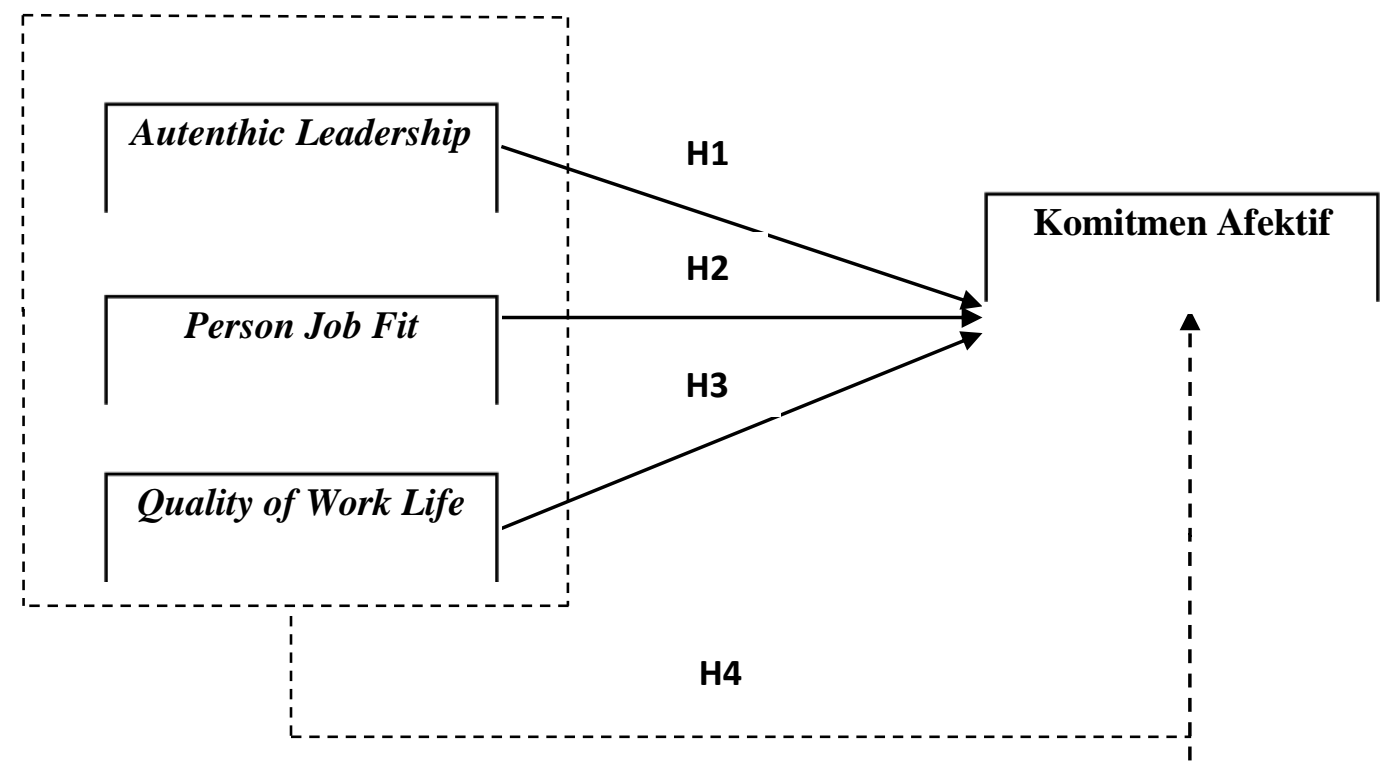

Gambar 1. Model Penelitian

$\mathrm{H}_{1}$ : Autenthic Leadership berpengaruh terhadap Komitmen Afektif Guru di SMK N 1 Ambal

$\mathrm{H}_{2}$ : Person Job Fit berpengaruh terhadap Komitmen Afektif Guru di SMK N 1 Ambal

$\mathrm{H}_{3}$ : Quality OfWork Life berpengaruh terhadap Komitmen Afektif Guru di SMK N 1 Ambal

$\mathrm{H}_{4}$ : Autenthic Leadership, Person Job Fit, dan Quality Of Work Life berpengaruh terhadap Komitmen Afektif Guru di SMK N 1 Ambal

\section{Metode Penelitian}

Objek penelitian adalah autenthic leadership, person job fit, dan qualty of work life di SMK Negeri 1 Ambal. Subjek dalam penelitian ini adalah Guru SMK N 1 Ambalyang berjumlah 37 orang.Variabel dependen dalam penelitian ini adalah komitmen afektif. Variabel independen adalah autenthic leadership, person job fit, dan quality of work life.

Dalam penelitian ini yang menjadi populasi adalah semua guru SMK N 1 Ambal. Peneliti mengambil sampel sebanyak 37 orang. Teknik sampling yang digunakan dalam penelitian adalah sampling jenuh dimana seluruh populasi digunakan sebagai sampel penelitian.

Dalam perhitungan pengolahan data, peneliti menggunakan alat bantu berupa program aplikasi komputer SPSS for windows 23.0. Adapun analisis yang digunakan yaitu Uji Instrumen meliputi (Uji Validitas dan Uji Reliabilitas), Uji Asumsi Klasik meliputi (Uji multikolinearitas, uji Heterokedastisitas dan Uji Normalitas, Uji Hipotesis yang meliputi: Uji Parsial (Uji t) dan Uji Koefisien Determinasi, Analisis Regresi Linear Berganda. 


\section{Hasil dan Pembahasan}

\section{Analisis Deskriptif}

Berdasarkan data yang diperoleh dari hasil penelitian yang dilakukan terhadap 37 orang. Maka dapat diidentifikasikan mengenai karakteristik responden sebagai berikut:

Tabel 1. Karakteristik Responden Berdasarkan Usia

\begin{tabular}{ccc}
\hline Usia (Tahun) & Jumlah (Orang) & Persentase (\%) \\
\hline$<30$ tahun & 13 & 35,13 \\
$30-40$ tahun & 9 & 24,32 \\
$>40$ & 15 & 40,55 \\
\hline Total & 37 & 100 \\
\hline
\end{tabular}

Sumber: Data primer diolah, 2021

Berdasarkan tabel 1 menunjukan bahwa responden berdasarkan usia yang berumur $<30$ tahun sebanyak 13 orang $(35,13 \%)$, berumur 30 - 40 tahun sebanyak 9 orang $(24,32 \%)$, berumur $>40$ sebanyak 15 orang $(40,55 \%)$, jadi responden terbanyak dalam penelitian ini adalah yang berumur $>40$.

Tabel 2. Karakteristik Responden Berdasarkan Jenis Kelamin

\begin{tabular}{ccc}
\hline Jenis Kelamin & Responden & Persentase (\%) \\
\hline Laki-laki & 17 & 45,94 \\
Perempuan & 20 & 54,06 \\
\hline Total & 37 & 100 \\
\hline
\end{tabular}

Sumber: Data primer diolah, 2021

Berdasarkan tabel 2 karakteristik responden berdasarkan jenis kelamin menunjukkan bahwa sebagian besar responden dalam penelitian ini adalah perempuan dengan jumlah 20 guru $(54,06 \%)$ dan sisanya sebanyak 17 guru $(45,94 \%)$ adalah laki-laki.

Tabel 3. Karakteristik Responden Berdasarkan Masa Kerja

\begin{tabular}{ccc}
\hline Usia (Tahun) & Jumlah (Orang) & Persentase (\%) \\
\hline $1-5$ tahun & 11 & 29,72 \\
$6-10$ tahun & 6 & 16,21 \\
$>10$ tahun & 20 & 54,06 \\
\hline Total & 37 & 100 \\
\hline
\end{tabular}

Sumber: Data primer diolah, 2021

Berdasarkan tabel 3 karakteristik responden berdasarkan masa kerja dapat diketahui bahwa masa kerja 1-5 tahun sebanyak 11 guru atau 29,72\%, masa kerja 6-10 tahun sebanyak 6 guru atau $16,21 \%$, dan masa kerja $>10$ tahun sebanyak 20 guru atau $54,06 \%$.

Tabel 4. Karakteristik Responden berdasarkan tingkat pendidikan

\begin{tabular}{ccc}
\hline Pendidikan & Jumlah (Orang) & Persentase (\%) \\
\hline S1 & 28 & 75,67 \\
S2 & 9 & 24,33 \\
\hline Total & 37 & 100 \\
\hline
\end{tabular}

Sumber: Data primer diolah, 2021 
Berdasarkan tabel 4 karakteristik responden berdasarkan tingkat pendidikan menunjukkan bahwa sebagian besar responden dalam penelitian ini paling banyak mempunyai tingkat pendidikan S1 sebanyak 28 guru $(75,67 \%)$ responden dengan tingkat pendidikan S2 sebanyak 9 guru $(24,33 \%)$.

\section{Analisis Statistik}

Analisis statistik dalam penelitian ini menggunakan data kuantitatif dengan menggunakan kuesioner sebagai alat bantu analisis yang berasal dari 37 responden yang bekerja sebagai guru PNS di SMK Negeri 1 Ambal.

\section{Uji Validitas}

Uji validitas dimaksud untuk mengetahui apakah butir-butir pernyataan dalam kuesioner cukup valid sebagai instrumen penelitian dengan ketentuan jika hasil $r$ hitungnya lebih besar dari $\mathrm{r}$ tabel dengan $\alpha<0,05$ maka dinyatakan valid. Nilai $\mathrm{r}$ tabel pada derajat kebebasan $(\mathrm{df})=\mathrm{n}-2$ atau $(37-2=35)$ maka didapat nilai $\mathrm{r}$ tabel sebesar 0,2746.

Hasil uji validitas variabel komitmen afektif sebagai berikut:

Tabel 5. Hasil Pengujian Validitas Variabel Komitmen Afektif

\begin{tabular}{ccccc}
\hline No & $\begin{array}{c}\text { Item } \\
\text { Pernyataan }\end{array}$ & r hitung & r tabel & Status \\
\hline 1 & Butir 1 & 0,810 & 0,274 & Valid \\
2 & Butir 2 & 0,846 & 0,274 & Valid \\
3 & Butir 3 & 0,742 & 0,274 & Valid \\
4 & Butir 4 & 0,837 & 0,274 & Valid \\
\hline
\end{tabular}

Sumber: Data primer diolah, 2021

Berdasarkan tabel 5 hasil pengujian validitas Komitmen Afektif menunjukkan bahwa Variabel Komitmen Afektif dinyatakan valid karena nilai korelasi pada kolom $r$ tabel 0,274 dengan tingkat signifikansi $<0,05$ sehingga dapat disimpulkan bahwa butir pernyataan variabel Komitmen Afektif dinyatakan valid.

Hasil uji validitas Variabel Autenthic Leadership sebagai berikut:

\begin{tabular}{ccccc}
\multicolumn{6}{c}{ Tabel 6. Hasil Pengujian Validitas Variabel } & Autenthic & Leadership \\
\hline No & Item Pernyataan & r hitung & r tabel & Status \\
\hline 1 & Butir 1 & 0,582 & 0,274 & Valid \\
2 & Butir 2 & 0,747 & 0,274 & Valid \\
3 & Butir 3 & 0,829 & 0,274 & Valid \\
4 & Butir 4 & 0,885 & 0,274 & Valid \\
\hline
\end{tabular}

Sumber: Data primer diolah, 2021

Berdasarkan tabel 6 hasil pengujian validitas Autenthic Leadership menunjukkan bahwa semua instrument Autenthic Leadership dinyatakan valid karena nilai korelasi $\mathrm{r}$ tabel 0,274 dengan tingkat signifikansi $<0,05$ sehingga dapat disimpulkan bahwa semua butir pernyataan variabel Autenthic Leadership dinyatakan valid.

Variabel Person Job Fit $\left(\mathrm{X}_{2}\right)$ 
Hasil uji validitas Variabel Person Job Fit sebagai berikut:

Tabel 7. Hasil Pengujian Validitas Variabel Person Job Fit

\begin{tabular}{ccccc}
\multicolumn{4}{c}{ Tabel 7. Hasil Pengujian Validitas Variabel Person Job Fit } \\
\hline No & $\begin{array}{c}\text { Item } \\
\text { Pernyataan }\end{array}$ & r hitung & r table & Status \\
\hline 1 & Butir 1 & 0,620 & 0,274 & Valid \\
2 & Butir 2 & 0,847 & 0,274 & Valid \\
3 & Butir 3 & 0,777 & 0,274 & Valid \\
4 & Butir 4 & 0,814 & 0,274 & Valid \\
5 & Butir 5 & 0,721 & 0,274 & Valid \\
6 & Butir 6 & 0,620 & 0,274 & Valid \\
\hline
\end{tabular}

Sumber: Data primer diolah, 2021

Berdasarkan tabel 7 hasil pengujian validitas Person Job Fit menunjukkan bahwa semua butir pertanyaan Person Job Fit dinyatakan valid karena nilai korelasi $r$ tabel 0,274 dengan tingkat signifikansi $<0,05$ sehingga dapat disimpulkan semua butir pernyataan variabel dinyatakan valid.

Hasil uji validitas Variabel Person Job Fit sebagai berikut:

Tabel 8. Hasil Pengujian Validitas Variabel Quality Of Work Life

\begin{tabular}{ccccc}
\hline No & $\begin{array}{c}\text { Item } \\
\text { Pernyataan }\end{array}$ & r hitung & r table & Status \\
\hline 1 & Butir 1 & 0,518 & 0,274 & Valid \\
2 & Butir 2 & 0,791 & 0,274 & Valid \\
3 & Butir 3 & 0,724 & 0,274 & Valid \\
4 & Butir 4 & 0,710 & 0,274 & Valid \\
\hline
\end{tabular}

Sumber: Data primer diolah, 2021

Berdasarkan tabel 8 hasil pengujian validitas Quality of Work Life menunjukkan bahwa semua butir pertanyaan Quality OfWork Life dinyatakan valid karena nilai korelasi pada kolom $\mathrm{r}_{\text {tabel }}$ 0,274 dengan tingkat signifikansi $<0,05$ sehingga dapat disimpulkan bahwa semua butir pernyataan variabel Quality of Work Life dinyatakan valid.

\section{Uji Reliabilitas}

Uji reliabilitas dilakukan dengan membandingkan nilai cronbach's alphadengan nilai $\mathrm{r}$ tabel atau dengan ketentuan nilai cronbach's alphalebih besar dari 0,6 maka dinyatakan reliabel. Hasil Uji Reliabilitas dapat dijelaskan sebagai berikut:

Tabel 9. Hasil Pengujian Reliabilitas Variabel

\begin{tabular}{lccc}
\hline \multicolumn{1}{c}{ Variabel } & Nilai Alpha & Nilai Kritis & Keterangan \\
\hline Komitmen Afektif & 0,822 & 0,6 & Reliabel \\
Autenthic Leadership & 0,770 & 0,6 & Reliabel \\
Person job fit & 0,828 & 0,6 & Reliabel \\
Quality OfWork Life & 0,636 & 0,6 & Reliabel \\
\hline
\end{tabular}

Sumber: Data primer diolah, 2021

Berdasarkan tabel 9 diatas, menunjukan bahwa hasil uji reliabilitas variabel komitmen afektif $\left(\mathrm{Y}_{1}\right)$, Autenthic Leadership $\left(\mathrm{X}_{1}\right)$, Person job fit $\left(\mathrm{X}_{2}\right)$ dan Quality Of Work Life $\left(\mathrm{X}_{3}\right)$ diatas 0,6 sehingga dapat disimpulkan semua variabel reliabel. 


\section{Uji Asumsi Klasik}

\section{Uji Multikolinieritas}

Model regresi dikatakan bebas dari multikolonieritas apabila memiliki VIF 10 dan mempunyai angka Tolerence 0,1. Berikut hasil uji multikolonieritas sebagai berikut:

Tabel 10. Hasil Pengujian Multikolonieritas

\begin{tabular}{lcc}
\hline \multirow{2}{*}{ Variabel Bebas } & \multicolumn{2}{c}{ Collonierity Statistics } \\
\cline { 2 - 3 } Autenthic Leadership $\left(\mathrm{X}_{1}\right)$ & Tolerance & VIF \\
Person Job Fit $\left(\mathrm{X}_{2}\right)$ & 0,889 & 1,125 \\
\hline Quality Of Work Life $\left(\mathrm{X}_{3}\right)$ & 0,856 & 1,169 \\
\hline
\end{tabular}

Sumber: Data primer diolah, 2021

Berdasarkan Tabel 10 menunjukan bahwa hasil uji multikolonieritas mempunyai nilai tolerance $>0,1$ dan nilai VIF $<10$, maka dapat disimpulkan tidak terjadi multikolonieritas antara variabel bebas, sehingga model regresi pada penelitian ini dapat dipakai.

\section{Uji Heterokedastisitas}

Uji heterokedastisitas digunakan untuk menguji apakah dalam model ini regresi terjadi ketidaksamaan variance dari residual satu pengamatan ke pengamatan yang lain.

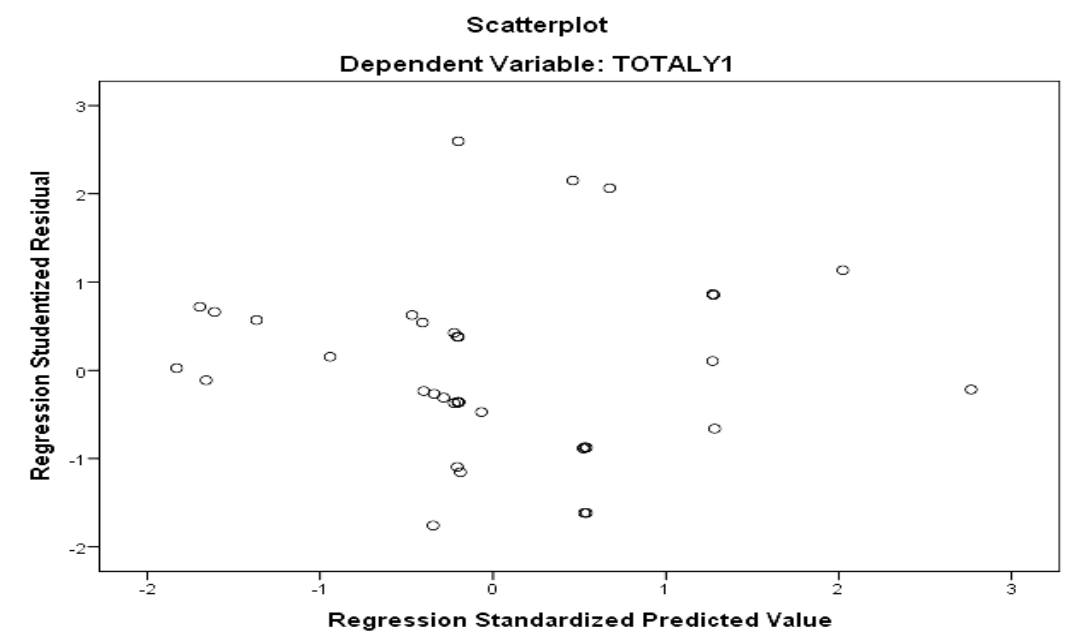

Gambar 2. Uji Heterokedastisitas

Sumber: Data primer diolah, 2021

Berdasarkan gambar Scatterplot diatas dari hasil output SPSS dapat diketahui bahwa tidak terdapat pola tertentu yang berupa titik-titik yang membentuk pola teratur, pada grafik menyebar diatas dan dibawah angka 0 (nol) pada sumbu $Y$, sehingga dapat disimpulkan bahwa model regresi pada penelitian ini tidak terjadi heterokedastisitas. 


\section{Uji Normalitas}

Menurut Ghozali (2013) uji normalitas bertujuan untuk menguji apakah dalam model regresi, variabel pengganggu atau residual memiliki distribusi normal.

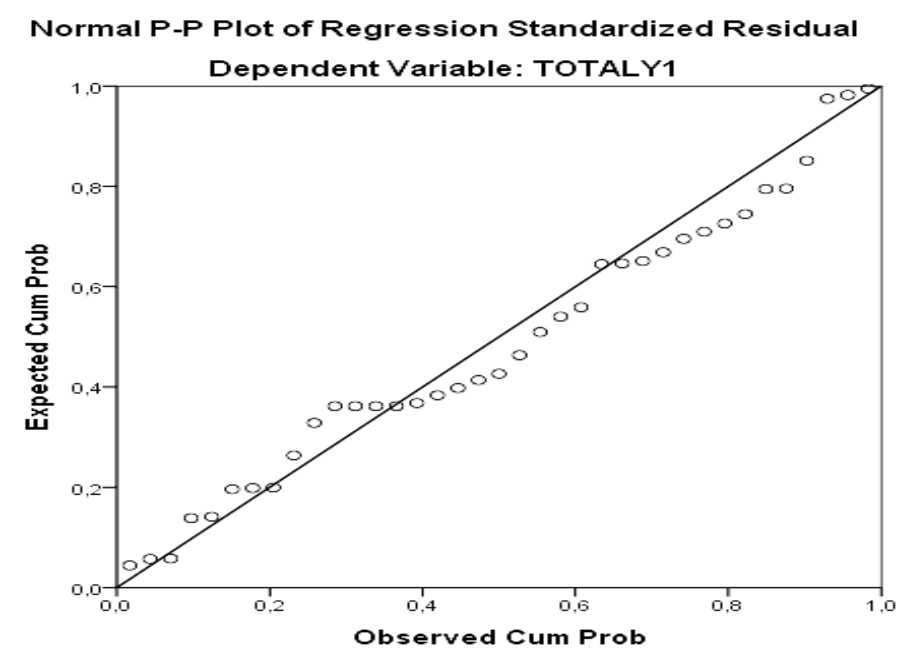

Gambar 3. Uji Normalitas

Sumber: Data primer diolah, 2021

Berdasarkan Gambar 3 hasil uji normalitas diatas, diketahui bahwa titik menyebar sekitar garis diagonal dan mengikuti arah garis diagonal, maka model regresi tersebut memenuhi normalitas.

\section{Analisis Regresi Linear Berganda}

Anlisis ini digunakan untuk mengetahui besarnya pengaruh variabel Autenthic Leadership, Person Job Fit dan Quality of Work Life terhadap Komitmen Afektif. Adapun hasil dari perhitungan regresinya adalah sebagai berikut:

Tabel 11. Hasil Perhitungan Analisis Regresi Linear Berganda

\begin{tabular}{lcccccc}
\hline \multirow{1}{*}{ Model } & \multicolumn{2}{c}{$\begin{array}{c}\text { Unstandardized } \\
\text { Coefficients }\end{array}$} & $\begin{array}{c}\text { Standardized } \\
\text { Coefficients }\end{array}$ & \multirow{2}{*}{ T } & Sig. \\
\cline { 2 - 4 } & B & Std. Error & Beta & & \\
\hline (Constant) & 5,374 & 4,015 & & & 1,339 &, 190 \\
Autenthic Leadership &,- 006 &, 149 &,- 006 &,- 038 &, 970 \\
Person Job Fit &,- 062 &, 163 &,- 059 &,- 382 &, 705 \\
Quality of Work Life &, 692 &, 181 &, 562 & 3,817 &, 001 \\
\hline
\end{tabular}

a. Dependent Variable: Y1

Sumber: Data primer diolah, 2021

\section{Uji Hipotesis Partial (Uji t)}

Uji $\mathrm{t}$ dilakukan untuk menunjukan satu variabel bebas (independent) secara individual menerangkan variabel terikat (dependent). Tingkat signifikansi yang digunakan dalam penelitian ini sebesar 5\% $(\alpha=0,05)$, jumlah sampel (n) sebanyak 37 , nilai $t_{\text {tabel }}$ sebesar 2,0324. Berikut hasil uji parsial (uji t) sebagai berikut: 
Tabel 12. Hasil Uji t

\begin{tabular}{lllllll}
\hline \multirow{1}{*}{ Model } & \multicolumn{2}{c}{$\begin{array}{c}\text { Unstandardized } \\
\text { Coefficients }\end{array}$} & $\begin{array}{c}\text { Standardized } \\
\text { Coefficients }\end{array}$ & \multirow{2}{*}{ T } & Sig. \\
\cline { 2 - 4 } & \multicolumn{2}{c}{ B } & Std. Error & Beta & & \\
\hline (Constant) & 5,374 & 4,015 & & 1,339 &, 190 \\
Autenthic Leadership &,- 006 &, 149 &,- 006 &,- 038 &, 970 \\
Person Job Fit &,- 062 &, 163 &,- 059 &,- 382 &, 705 \\
Quality OfWork Life &, 692 &, 181 &, 562 & 3,817 &, 001 \\
\hline
\end{tabular}

a. Dependent Variable: $\mathrm{Y} 1$

Sumber: Data primer diolah, 2021

Berdasarkan perhitungan, maka diperoleh nilai $t_{\text {tabel }}$ sebesar 2,0324 sehingga dapat dilihat hasil uji t yang menunjukkan hasil pengaruh tiap variabel.

Tabel 13. Hasil Pengaruh Variabel

\begin{tabular}{cccccc}
\hline $\begin{array}{c}\mathbf{N} \\
\mathbf{0}\end{array}$ & $\begin{array}{c}\text { Hipotesi } \\
\mathbf{s}\end{array}$ & Variabel & $\mathbf{t}_{\text {hitung }}$ & $\mathbf{t}_{\text {tabel }}$ & $\begin{array}{c}\text { Konseptu } \\
\text { al }\end{array}$ \\
\hline 1 & $\mathrm{H}_{1}$ & $\begin{array}{c}\text { Autenthic Leadership } \\
\text { terhadap komitmen afektif } \\
2\end{array}$ &,- 038 & 2,032 & Ditolak \\
3 & $\mathrm{H}_{2}$ & $\begin{array}{c}\text { Person Job Fit terhadap } \\
\text { komitmen afektif }\end{array}$ &,- 382 & 2,032 & Ditolak \\
& $\mathrm{H}_{3}$ & $\begin{array}{c}\text { Quality Of Work Life } \\
\text { terhadap komitmen afektif }\end{array}$ & 3,817 & 2,032 & Diterima \\
\hline
\end{tabular}

Sumber: Data primer diolah, 2021

\section{Uji Simultan (Uji F)}

Uji Simultan (Uji F) digunakan untuk mengetahui apakah terdapat hubungan yang nyata antara variabel independen $(X)$ dengan variabel dependen $(Y)$ secara bersama-sama.

Tabel 14.Hasil Pengujian Uji F

\begin{tabular}{llllll}
\hline Model & Sum of Squares & Df & Mean Square & F & Sig. \\
\hline Regression & 31,351 & 3 & 10,450 & 5,495 &, $004^{\mathrm{b}}$ \\
Residual & 62,757 & 33 & 1,902 & & \\
\hline Total & 94,108 & 36 & & & \\
\hline a. Dependent Variable: Komitmen Afektif & & & \\
b. $\quad$ Predictors: (Constant), Quality Of Work Life, Person Job Fit, Autenthic \\
$\quad$ Leadership \\
Sumber: Data primer diolah, 2021
\end{tabular}

Berdasarkan tabel diatas, dapat diketahui bahwa $\mathrm{F}_{\text {hitung }}$ adalah 5,495 $>\mathrm{F}_{\text {tabel }}$ sebesar 2,88 dan mempunyai nilai signifikansi sebesar 0,004 < 0,05 yang berarti bahwa variabel autenthic leadership, person job fit, dan quality of work life secara bersama-sama berpengaruh signifikan terhadap kinerja guru PNS di SMK Negeri 1 Ambal. 


\section{Koefisien Determinasi ( $\left.\mathbf{R}^{2}\right)$}

Koefisien determinasi digunakan untuk mengukur besarnya kontribusi variabel independen terhadap variabel dependen. Hasil pengujian koefisien determinasi dapat dilihat pada tabel sebagai berikut:

Tabel 15. Hasil Pengujian Koefisien Determinasi

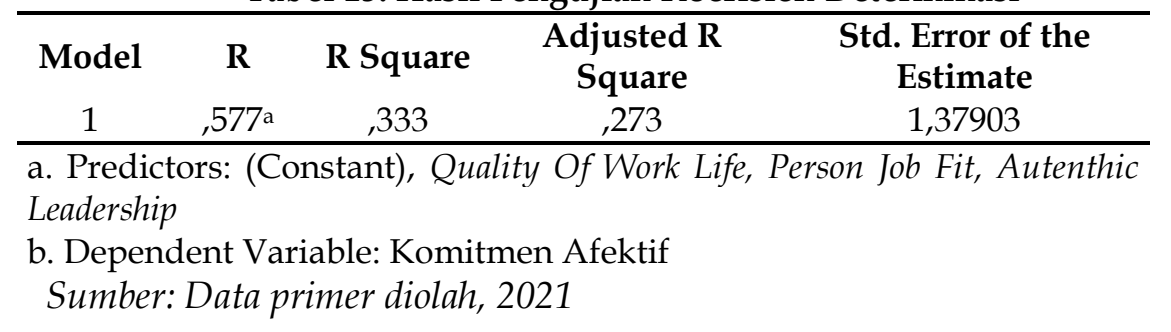

Berdasarkan tabel diatas, dapat dianalisis bahwa nilai koefisen Adjusted $R$ Square sebesar 0,273 atau 27,3\% Komitmen Afektif Guru PNS SMK Negeri 1 Ambal dipengaruhi oleh Autenthic Leadership (X1), Person Job Fit (X2), dan Quality Of Work Life (X3), sedangkan sisanya $(100 \%-27,3 \%=72,7 \%)$ dipengaruhi oleh variabel lain yang berada diluar penelitian ini

\section{Penutup dan Saran}

Berdasarkan hasil pembahasan analisis data yang melalui pembuktian terhadap hipotesis dari permasalahan yang diangkat mengenai fakto-faktor yang mempengaruhi komitmen afektif guru PNS SMK Negeri 1 Ambal, maka dapat diperoleh kesimpulan sebagai berikut:

1. Hasil penelitian menunjukan bahwa variabel Autenthic Leadership tidak berpengaruh terhadap komitmen afektif guru PNS di SMK Negeri 1 Ambal.

2. Variabel Person Job Fit tidak berpengaruh terhadap komitmen afektif guru PNS di SMK Negeri 1 Ambal.

3. Variabel Quality of work life berpengaruh signifikan terhadap komitmen afektif guru PNS di SMK Negeri 1 Ambal.

4. Variabel independen (Autenthic Leadership, Person Job Fit, dan Quality Of Work Life) secara bersama sama atau secara simultan berpengaruh signifikan terhadap variabel dependen (Komitmen Afektif guru PNS).

\section{Referensi}

Angelia, N. (2013). Hubungan antara kualitas kehidupan kerja dengan komitmen organisasi pada karyawan perusahaan Genteng Mutiara. Jurnal Psikologi, 2(1).

Anindita, A. (2020). Pengaruh Person Organization Fit dan Person Job Fit Terhadap Kinerja Pegawai Melalui Komitmen Afektif Pada Kantor Cabang Dinas Pendidikan Wilayah Kota Surabaya Provinsi Jawa Timur. Jurnal Ilmu Manajemen (JIM), 8(1).

Ardana, I. K., Mujiati, N. W., \& Utama, I. W. M. (2012). Manajemen Sumber Daya Manusia. Yogyakarta: Graha Ilmu.

Davis, K., \& Newstrom, J. W. (2012). Perilaku dalam Organisasi. Jakarta: Erlangga.

Fitriyani, P. N. (2019). Pengaruh Iklim Psikologis, Quality of Work Life (QWL) Terhadap Keterlibatan Kerja Melalui Komitmen Afektif Sebagai Variabel Intervening Pada Pegawai Dinas Pendidikan Kabupaten Kebumen. Skripsi. Manajemen. 
Hanum, P. N. (2014). Analisis Pengaruh Person Job-Fit dan Person Organization Fit terhadap Work Engagement Karyawan pada PT. Arvindo Cipta Gemilang, Kantor Pusat. Library Binus, 2014-1-00378-MN.

Kruse, K. (2013). What is authentic leadership?. Diunduh dari http://www.forbes.com/ sites/kevinkruse/2013/05/12/what-is-authenticleadership/\#197b2f012ddd. Diakses Tanggal 12 Desember 2020

Mayora, M., \& Purwanto, E. (2019). Pengaruh kepemimpinan transformasional dan kepemimpinan otentik terhadap niat keluar karyawan dengan mediasi komitmen afektif. Journal of Business \& Applied Management, 12(2), 155-168.

Meirizki, A. N. (2018). Pengaruh transformational leadership dan authentic leadership terhadap follower psychological capital pada karyawan grand cempaka business hotel di Jakarta Pusat. SKRIPSI-2018.

Murniasih, E., \& Sudarma, K. (2016). Pengaruh Persepsi Dukungan Organisasi dan Kompetensi pada Kinerja Karyawan Dimediasi Komitmen Afektif. Management Analysis Journal, 5(1).

Nurdiyana, D., Tohirin, \& Ilhamdi. (2019). Perilaku Organisasi Modern. Jakarta: Mitra Wacana Media

Oh, J., \& Oh, S. (2017). Authentic leadership and turnover intention: does organizational size matter?. Leadership \& Organization Development Journal, 38(7).

Robbins, S. P., \& Judge. T. A. (2008). Perilaku Organisasi. Jakarta: Salemba Empat.

Siagan, S. P. (2010). Manajemen Sumber Daya Manusia. Jakarta : Bumi Aksara

Sugiyono. (2016). Metode Penelitian Bisnis. Alfabeta.

Undang-Undang Guru dan Dosen Nomor 14 Tahun 2005 pasal 7 (ayat 1b)

Undang-Undang Republik Indonesia Nomor 14 Tahun 2005 pasal 20 tentang Guru dan Dosen 